\title{
Jogos teatrais e improvisação: por uma educação filosófica na infância ${ }^{1}$
}

\section{Theater games and improvisation: for a philosophical education in childhood}

Raquel Aline Zanini ${ }^{2}$

Geraldo Balduino Horn ${ }^{3}$ 


\section{Resumo}

Este artigo procura mostrar, a partir de um estudo exploratório, possíveis interfaces entre filosofia e teatro. Defende a necessidade de proporcionar às crianças um espaço próprio de expressão como "lugar de fala" rompendo, assim, com a condição de infante - sem fala. A filosofia é compreendida enquanto práxis, que parte do reconhecimento dos carecimentos do sujeito (Heller, 1983). Aliando prática de jogos teatrais e improvisação com base na teoria de Viola Spolin (2010) e nas reflexões de Walter Benjamin (2009), conclui que este entrelaçamento torna possível conduzir o processo educativo de modo a garantir às crianças a realização da infância.

Palavras-chave: Infância; jogos teatrais; improvisação; educação filosófica

\section{Abstract}

This article seeks to show, from an exploratory study, possible interfaces between philosophy and theater. It defends the need to provide children with their own space of expression as a "place of speech", thus breaking the condition of infant - without speech. Philosophy is understood as praxis, which starts from the recognition of the subject's needs (Hwllwe, 1983). Combining the practice of theater games and improvisation based on Viola Spolin's theory (2010) and Walter Benjamin's reflections (2009), he concludes that this intertwining makes it possible to conduct the educational process in order to guarantee children the realization of childhood.

Keywords: Childhood; theater games; improvisation; philosophical education

E-ISSN: 2358.6958

\footnotetext{
1 Este artigo está vinculado a dissertação intitulada Educação filosófica e infância: o jogo teatral como possibilitador dessa relação a partir dos carecimentos das crianças (Zanini, 2019).

2 Atriz, Mestre em Educação - Universidade Federal do Paraná (UFPR). Trabalha na Secretaria Municipal da Educação de Curitiba e no Colégio Estadual do Paraná (SEED/PR) - raquel.zanini@hotmail.com

3 Prof. Dr. Curso de Filosofia - graduação e pós-graduação - Universidade Federal do Paraná (UFPR) - gbalduino.ufpr@gmail.com
} 


\section{Prólogo}

\begin{abstract}
[...]
O menino aprendeu a usar as palavras. Viu que podia fazer peraltagens com as palavras. E começou a fazer peraltagens.
\end{abstract}

Foi capaz de interromper o voo de um pássaro botando ponto final na frase.

[...]

(Manoel de Barros - O menino que carregava água na peneira, 2010)

A arte, de modo geral, e a filosofia sempre foram áreas do conhecimento relegadas a segundo plano dentro das escolas e nos seus currículos (Koudela e Almeida Junior, 2015, p. 176-177). A presença do teatro, em especial, é resultado de lutas e da defesa deste como conteúdo programático. Com a criação da Lei de Diretrizes e Bases da Educação Nacional (LDB, Lei no 9394/ 1996) rompe-se com a ideia de uma educação artística, fruto da Ditadura Militar, e passa-se a propor o ensino de arte, reconhecido como conteúdo curricular obrigatório.

Neste processo, que acarretou um deslocamento de paradigmas no campo do ensino da arte, foi necessário aos estudiosos do teatro-educação considerarem a necessidade de não cair na armadilha do espontaneísmo ${ }^{4}$, endossando apenas a técnica em detrimento da teoria (Koudela; Almeida Junior, p. 177). Neste sentido, surgem no Brasil diversas práticas pedagógicas de ensino do teatro, atentas à história e à formação estética dos estudantes, garantindo seu lugar como área do conhecimento.

Do mesmo modo ocorreu com o ensino de filosofia proposto para crianças que, através da criação, promoção e implementação do Programa de Filosofia para Crianças, de Matthew Lipman (1990)5, chega às escolas públicas brasileiras e propõe uma prática filosófica desde os anos iniciais do ensino fundamental com objetivo de desenvolver o pensar, amparado pela prática de uma Comunidade de Investigação centrada na realização de exercícios de lógica. Tanto a prática teatral em sala de aula quanto a filosófica demandam subsídios e proposições por parte do professor, de modo que pensar no entrelaçamento destas áreas tem a ver com a possibilidade de trazer às crianças subsídios para suas cenas, sem caráter enciclopédico, mas buscando estar em consonância com seus carecimentos (Heller, 1983), expressos nas

\footnotetext{
4 Tanto em seu verbete "teatro-educação" (Koudela; Almeida Junior, 2015, p. 177) quanto neste texto com Santana (2005, p. 148), Koudela busca evidenciar que a prática e o ensino de teatro na escola precisa ser revisto e que sua marca não é espontaneísta, mas tem o compromisso com o ensino, aprendizagem e formação do ser; ressalva importante pois, como indica, a "dicotomia e polarização de objetivos e técnicas agravaram-se durante os últimos trinta anos no Brasil. Através da influência do escolanovismo e da postura espontaneísta, pode-se caracterizar uma tendência que ancora os objetivos educacionais da atividade de teatro na escola na dimensão psicológica do processo de aprendizagem", processo contra o qual os pedagogos teatrais lutam a fim de romper com uma defesa do teatro no currículo escolar a partir da busca por "objetivos comportamentais" a serem atingidos. O teatro é uma área do conhecimento que merece seu espaço no currículo escolar não como instrumento, mas como conhecimento.

5 Apesar do caráter mercadológico e instrumental desta proposta, foi a partir dela que se desenvolveram outras teorias e propostas de trabalho de filosofia com crianças, atualmente mais presentes nas escolas privadas. Para mais informações sobre o programa lipmaniano e sua chegada ao Brasil é possível ler a pesquisa de Muranaka, 2007. Para práticas atuais em escola pública há o livro Kohan, 2012, que apresenta sua prática em escolas da cidade de Duque de Caxias; e de Oliveira, 2004.
} 
dúvidas e questionamentos que surgem naturalmente nos jogos teatrais e nas improvisações e acabam por proporcionar ricos diálogos entre as crianças, demandando explicações e troca de informações e conhecimentos entre as crianças.

Reconhecendo que é característico da infância o questionamento: "o que é isto?", "como?", "por quê?", "que finalidade tem isto?", "por que tem de ser feito assim?", "por que não pode ser feito desse outro modo?" (Matthews, 2001, p. 38) e que a filosofia tem como ponto de partida a formulação de questões "pueris", pois o filósofo formula "propositalmente as perguntas pueris: elas são o terreno no qual ele pode espargir as sementes do seu saber, a partir do qual desenvolvem-se os primeiros esboços do sistema até chegar à sua plena maturidade" (Heller, 1983, p. 22), estreita relação entre ambas áreas do conhecimento foi se tornando cada vez mais clara e necessária.

Portanto, este estudo investiga a possibilidade de entrelaçar uma educação filosófica à prática de jogos teatrais e improvisação de modo a proporcionar às crianças a realização da sua infância durante seu processo formativo. Propõe também o desenvolvimento das crianças enquanto atores sociais, rompendo com sua condição de infante ${ }^{6}$, sem fala, reconhecendo o processo educacional como momento para realização da infância (Benjamin, 2009). Atento à percepção infantil, parte-se da compreensão das dimensões política e estética da educação proporcionando às crianças a reflexão filosófica a partir dos seus carecimentos (Heller, 1983).

Agnes Heller traz em sua obra a concepção de filosofia enquanto práxis, uma filosofia radical, que não compreende a filosofia como dogma ou conteúdo a ser transmitido, mas como "modo de vida", pois ao partir do carecimento (necessidades) dos seres, social e historicamente localizados, busca-se na filosofia elementos para escolher um modo de agir, viver e pensar (Heller,1983).

Importante ressaltar que esta prática conjunta é pensada de modo a não instrumentalizar nenhuma das áreas do conhecimento, mas garantir a ambas seu estatuto de conhecimento e seu espaço curricular. A teoria da capacidade mimética de Walter Benjamin (2012a, p. 117) e seu Programa de um teatro infantil proletário (2009, p. 113) foram os propulsores deste itinerário ao proporcionar o reconhecimento de que o jogo é a escola ontogenética da capacidade mimética, pois para o filósofo esta passa de uma produção de semelhanças sensíveis às não-sensíveis, como a linguagem e a escrita. Ou seja, a criança vai transitando da expressão através do jogo e da mímesis mais fisicalizada à destreza na utilização da linguagem e da escrita, em detrimento do corpo, para expressar-se.

Assim, entende-se que os carecimentos da infância podem ser identificados a partir de uma educação que garanta um "contexto" formativo, não um ideário sujeitado às imposições do conhecimento programático. É através do jogo que a criança tem garantida a realização da sua infância, pois neste processo ela está em relação direta com seus pares e pode expressar-se, dialogar e produzir conhecimentos. A im-

6 Gagnebin $(2005,172)$ vai indicar que o termo "infância" não remete a uma idade determinada, mas àquilo que caracteriza a fase inicial da vida humana, ou seja, a incapacidade e a ausência da fala. Lajolo (2016, p. 324) vai indicar que a palavra infância e seus cognatos constroem-se a partir do prefixo in que indica negação e do sufixo fante, particípio presente do verbo latino fari, que significa falar ou dizer, deste modo, o infante é aquele que não fala, o que historicamente acaba por caracterizar a criança como aquela que não possui o direito ao discurso, como pessoa que não está autorizada pela sociedade a fazer uso da palavra. 
provisação e a encenação garantem a ela lugar de fala no espaço escolar, momento no qual "o mais alto converte-se no mais baixo de todos [...] assim as crianças sobem ao palco durante a encenação e ensinam e educam os atentos educadores" (Benjamin, 2009, p. 118), tornando-se possível pensar numa barbárie positiva na educação, que lhes proporcione uma outra relação com o conhecimento, a memória e o outro.

\section{Episódio 1}

Em Benjamin (2009, p. 114) o teatro é o lugar da educação dialeticamente determinada, por proporcionar ã criança a relação com seus pares, a expressão daquilo que percebe e pensa do seu contexto, assim como, por permitir à criança um espaço de fala e criação; neste sentido que, compreendendo a filosofia como práxis, como aquela que possibilita ao ser a escolha de um modo de vida, a partir dos seus carecimentos do sujeito, o que implica em ouvir a criança, dar espaço para seus "porquês", suas inquietações, observar de modo atento sua relação com seus pares e seu meio, evidência o modo como estas duas área do conhecimento tornaram-se aliadas importantes.

O jogo aqui é compreendido, a partir da perspectiva benjaminiana, como aquele que auxilia no desenvolvimento ontogenético da capacidade mimética do ser humano, que transita da produção de semelhanças sensíveis à produção de semelhanças não-sensíveis, como a linguagem e a escrita (Benjamin, 2012a, p. 117). Essa mutabilidade da capacidade mimética do ser humano é fundamental para pensar este entrelaçamento da filosofia com os jogos teatrais e a improvisação: em Benjamin (Idem) temos não o declínio da capacidade mimética no adulto, mas sua transformação, pois cada época descobrirá e inventariará semelhanças. A mímesis não é reprodução, mas sim reconhecimento e a produção das semelhanças, ela está ligada "por definição ao jogo e ao aprendizado, ao conhecimento e ao prazer de conhecer" (Benjamin, 2012a, p. 117).

Essa compreensão é cara ao contexto atual da educação, pois além de estarmos imersos no discurso de uma concepção de educação como "aprender a aprender" mantemos práticas que expressam o alheamento à condição da infância em relação ao mundo adulto, deixando-as à margem, preparando-as tecnicamente para serem cidadãs ativas na sociedade democrática, não promovendo um processo educativo que lhes proporcione espaço de fala, que lhes permita o uso da criação no processo de produção de semelhanças, deixando de lado o caráter estético e filosófico da educação.

Em suma, quando se trata de ensinar, o processo se dá por meio da transmissão enciclopédica de conteúdos, sem problematização, diálogo e reflexão, entendendo o professor como aquele que deve levar as crianças ao desenvolvimento de sua capacidade racional e intelectual. Este aspecto é enfatizado principalmente quando se trata de pensar o ensino de filosofia para crianças e apontar a impossibilidade de sua realização pelo seu nível de abstração conceitual e complexidade que exige, o que a torna imprópria para a infância.

O afastamento da relação entre a arte e a vida (Bakhtin, 2011, p. XXXIII), entre a filosofia e a realidade devem-se, em parte, à divisão social do trabalho, à compre- 
ensão de que a arte não responde pela vida e ao afastamento entre o receptor e o criador seja da arte, seja da filosofia (Heller, 1983), neste processo destituiu-se o ser humano da sua capacidade criadora e a filosofia e a arte deixaram de ser parte orgânica da vida cotidiana tornando todo sujeito apenas receptor, consumidor. No caso da filosofia, como indica Heller (Heller, 1983); esse movimento acaba por tornar legítimo apenas o discurso daquele que, ou torna-se filósofo profissional ou atinge um status significativo dentro de alguma área profissional. Essa compreensão evidencia a manutenção da criança como in-fante, aquele que não fala, que não possui status social algum e por isso não pode manifestar-se socialmente.

Entretanto, quando a criança e o adulto experimentam o momento criativo da filosofia, da arte, por meio de uma experiência com a linguagem, por exemplo, inicia-se "um diálogo mais profundo entre os limites do conhecimento e da verdade nas relações entre as pessoas", pois é o processo de conhecer e o modo como se dá que gerará crítica ou conformismo ao dado, que suscitará a necessidade de questionamento ou apreensão. Como colocam Pereira e Jobim e Souza (1998, p. 36), o mundo da criança, em que ela vive e se relaciona com o outro "é um claro-escuro de verdade e engano. Nesse mundo, a verdade não é dada, não está acabada, impressa de forma imutável na consciência humana", a verdade se "faz constantemente nas relações sociais e por meio delas", entendendo que a "linguagem é o local da produção de sentidos e o ponto para o qual jogo, criatividade e pensamento crítico convergem" (Pereira e Jobim e Souza,1998, p. 36).

Essa compreensão da verdade faz refletir acerca da relação que há com a história, a cultura, a sociedade, a filosofia e a arte, de modo a pensar qual seja a possibilidade de propor novas práticas e lugares para ambas áreas dentro da escola. Pensá-las dentro do recorte epistemológico adotado no presente artigo é o que nos propomos.

\section{Episódio 2}

Walter Benjamin ao conhecer o trabalho de Asja Lacis ${ }^{7}$ propõe-se a escrever um programa da sua prática teatral realizada com crianças e jovens russos que haviam sido abandonados por suas famílias, os chamados besprisomye, que por este fato não haviam passado por uma experiência de vida familiar e nem mesmo um processo de escolarização. $O$ intuito de Lacis era proporcionar a estes uma formação estética, 0 que, para Benjamin, já era uma consideração recorrente em seus escritos ${ }^{8}$, considerando-se que se deveria atentar à percepção infantil e às especificidades desta fase.

Ao elaborar este programa para Lacis o filósofo demarca como elemento substancial a formação política e estética da criança, garantindo a elas a realização de sua infância, sem a imposição de ideários de vida, mas atento às suas especificidades, proporcionando-lhes um contexto formativo, no qual o professor esteja atento aos

\footnotetext{
7 Asja Lacis faz parte de um grupo de artistas que se preocuparam, na década de 1920, com o aperfeiçoamento do processo educativo de modo a aprofundá-lo e facilitá-lo. Lacis estava na Rússia que após a 1a Guerra Mundial, a Revolução e a crise econômica de 1921-1922, gerou um contingente de sete milhões de jovens e crianças abandonadas, os chamados besprisomye, seu intuito era empreender uma educação estética para essas crianças que não haviam passado nem por um processo de escolarização, tampouco haviam tido vida familiar, ou seja, sua educação por instituições tradicionais era impossível. (Koudela, 1991, p. 27)

8 Isso pode ser observado em seus escritos: Uma pedagogia comunista, Chichleuchlauchra e Programa de um teatro infantil proletário, reunidos na obra Reflexões sobre a criança, o brinquedo e a educação (2009).
} 
gestos infantis ${ }^{9}$ (Benjamin, 2009, p. 115).

Esse "gesto infantil", possível de ser visualizado nos jogos teatrais e na forma improvisacional do teatro, é reconhecido como passível de ser potencializado através de oficinas organizadas pelo(a) professor(a) que instiguem as crianças a se expressarem do modo mais autêntico. Os enunciados podem ser produzidos na relação com seus pares. É a partir da forma que a criança vai, no transcorrer das aulas, aprendendo novos conteúdos. Também os materiais utilizados na produção artística vão ganhando formas mais delineadas após a reflexão filosófica, aqui, especificamente, entende-se que a linguagem é este material, que representa a dramaturgia da criança.

Esta prática enseja às crianças a inserção no trabalho coletivo, o que implicará na troca e no reconhecimento das diferenças, assim como na resolução de tensões do trabalho coletivo, que são "os verdadeiros educadores" (Benjamin, 2009, p. 114). Seu objetivo não é de modo algum a conclusão, mas sim o processo de "colocar" e "resolver" tensões. Entende-se, a partir desta pesquisa, que essas tensões têm a ver com a evidenciação também de carecimentos humanos, principalmente no que diz respeito à relação com o outro, e, neste sentido, colabora para a prática filosófica pois, ao problematizarem no coletivo e, após o diálogo e a investigação, produzirem, por meio da improvisação teatral, uma cena, as crianças vão juntas construindo a compreensão, resolvendo as tensões ali geradas e transpondo a mera opinião, para o conhecimento filosófico.

Benjamin (2009) evidencia que as tensões geradas no fazer teatral podem chegar a tal intensidade que "sofrimentos encenados podem converter-se em sofrimentos autênticos", pois para a criança, no teatro, a realidade e o jogo se fundem, visto que a criança neste processo não faz-de-conta, mas (re)vive essa realidade, o que possibilita encontrar na repetição uma marca da infância (Benjamin, 2009, p. 113-114).

A lei da repetição, que se configura como a alma do jogo para as crianças, tem a fórmula mágica do "mais uma vez", e está atrelado ao começar de novo, do início, sempre voltando a criar para si o fato vivido, esse desejo pela repetição,

\footnotetext{
Não se trata apenas de um caminho para assenhorar-se de terríveis experiências primordiais mediante o embotamento, conjuro malicioso ou paródia, mas também de saborear, sempre de novo e de maneira mais intensa, os triunfos e as vitórias. $\mathrm{O}$ adulto, ao narrar uma experiência, alivia o seu coração dos horrores, goza duplamente uma felicidade. A criança volta a criar para si todo o fato vivido, começa mais uma vez do início [...] a essência do brincar não é um "fazer como se", mas um "fazer sempre de novo", transformação da experiência mais comovente em hábito. (Benjamin, 2009, p. 101-102)
}

"Fazer sempre de novo", repetir o jogo, traz também a marca dos gestos, das ações que viram "sinais", muitos desses se repetem a cada nova cena e expressam a potência que o processo pode ter para compreender as crianças e seus carecimentos através da observação. Esse é outro aspecto central na colocação benjaminiana: a observação, que deve ser o cerne da educação em detrimento de sua influência mo-

9 Importante ressaltar que essa educação estética ambicionada não tinha como objetivo a transmissão de informações ou ensinamentos, Benjamin evidencia que isso deve se dar apenas mais tarde, pois é através da práxis, ou seja, de um contexto que se educará a criança e não sob um ideário. Deste modo, ele renuncia às "práticas 'imparciais', 'compreensivas', 'sensíveis', como também as educadoras 'cheias de amor pela criança', que impõe às crianças a decoreba, a reprodução de ideias prontas. (Buck-Morss, 2002) 
ral. Assim, o professor, por meio da observação e atenção aos gestos infantis, pode libertá-los "do reino da mera fantasia" de modo a "conduzi-los à sua execução nos conteúdos" através de oficinas (Benjamin, 2009, p. 115).

Na prática, que Lacis (Koudela,1991, p.29) contextualizou a Benjamin, ela "dava às crianças a possibilidade de exercitarem suas aptidões através do desenho e pintura, música, escultura, ginástica e teatro", a fim de propiciar o "desenvolvimento do gesto infantil até as diferentes formas de expressão" citadas acima, mas, como indica Benjamin, em todas estas a "improvisação permanece como central [...] predomina; ela é a constituição da qual emergem os sinais, os gestos sinalizadores" (Benjamin, $2009, p, 116)$. Esse processo, tem como intuito o desenvolvimento estético e político das crianças, em detrimento da imposição moral e ideológica.

Assim, essa educação estética e política, partindo do teatro na verdade tinha nas oficinas a possibilidade do aperfeiçoamento e reconhecimento da capacidade expressiva pela criança, na improvisação a relação com seus pares e na encenação o processo de ensino dos adultos, pelas crianças (Benjamin, 2009, p, 116).

Com base nestas provocações benjaminianas, busca-se na pedagogia teatral e no histórico das investigações acerca do ensino desta linguagem compreender como esta prática pode a ocorrer na escola de modo a garantir ao teatro seu lugar enquanto área do conhecimento em correlação com a filosofia. Assim, chega-se até Viola Spolin ${ }^{10}$ e sua teoria do jogo teatral (Koudela; Almeida Junior, 2015, p. 109), sondando-se a possibilidade desta ser a base para empreender o princípio da prática teatral entrelaçada a educação filosófica.

Spolin (2010) foi responsável pela organização de uma metodologia, os spolin games ou jogos improvisacionais de regras, com intuito de ensinar para crianças, jovens e adultos, atores e não atores, a linguagem artística do teatro, entendendo que "através do processo de jogos e da solução de problemas de atuação, as habilidades, a disciplina e as convenções do teatro podem ser aprendidas", caracterizando-se por serem, ao mesmo tempo, exercícios teatrais e atividades lúdicas que aliadas formam a base para o ensino desta linguagem.

Apesar da distância temporal e do caráter sistemático da proposta de Spolin (2010), evidencia-se uma tênue relação possível entre ela e a proposta de Asja Lacis e o programa escrito por Walter Benjamin (Koudela, 1991, p. 26), pois em ambas pressupõem-se que o "atuante se torna artesão de sua própria educação, produzida livremente por ele mesmo, embora dentro dos parâmetros de articulação de uma linguagem artística - o teatro e a improvisação teatral" (Koudela; Almeida Junior, 2015, p. 109) $)^{11}$.

10 Viola Spolin (2010, p. 342) foi a responsável pela organização dos jogos teatrais, sua contribuição é importante principalmente no que diz respeito a distinção entre dramatic play (jogo dramático) e game (jogo de regras) que, do ponto de vista teórico, tem sua distinção em relação ao corpo do participante: enquanto no jogo dramático impera o fantasiar e o "atuar e/ou viver através de velhas situações de vida (ou de outra pessoa) para descobrir como se adequar a elas; jogo comum entre as crianças de maternal quando procuram tornar-se aquilo que temem, ou admiram ou não entendem; o jogo dramático, se continuado na vida adulta, resulta em devaneios, identificação com personagens de filmes, teatro e literatura; elaborar material velho em oposição a uma experiência nova; viver o personagem; pode ser usado como uma forma simplificada do psicodrama, não é útil para o palco"; o game, jogo de regras, tem a ver com um processo de aprendizagem já mais consciente da representação corporal que, para ela "busca evitar uma imitação irrefletida, mera cópia" através do princípio da physicalization (Koudela; Almeida Junior, 2015, p. 109).

11 Ressaltamos aqui a possibilidade de discussão, em artigo subsequente, acerca da distinção e distância entre os jogos e oficinas propostos por Asja Lacis, nos quais Benjamin se baseia para a elaboração do Programa para um teatro infantil proletário (2009) e os jogos teatrais de Bertold Brecht, visto que há uma relação de proximidade muito grande entre Benjamin e Brecht, principalmente porque há muitos escritos de Benjamin sobre sua obra (reunidos no volume Ensaios sobre Brecht), mas que, como indica Koudela (1991, p. 26-27), não se sabe se Benjamin algum dia contou para Brecht sobre a prática de Asja Lacis com os menores abandonados e nem que tenha Ihe dado o manuscrito do seu Programa para ler.

Raquel Aline Zanini,

Geraldo Balduino Horn 
Essa produção livre de sua própria educação não tem a ver com o espontaneísmo, como indica Koudela e Santana (2005, p. 148), mas sim tem correlação direta com possibilidade de espaço de criação através da apreensão dos elementos que compõe o fazer teatral. Nesse sentido, ao pensar esse entrelaçamento filosófico-teatral pode-se, partindo dos jogos teatrais, que inserem a criança na linguagem cênica de forma lúdica, principiar o processo de discussões e reflexão entre as crianças, proporcionando ao professor o espaço-tempo de observação dos gestos infantis. Essa prática com o jogo teatral traz em si outro elemento fundamental: é através dela que a criança, além de poder se expressar, vai apreendendo os elementos constituintes da linguagem teatral: a relação com o público, os modos de se comunicar, a relação do corpo com a expressão, seus elementos cênicos.

Após essa atividade o professor pode propor a improvisação teatral, ou seja, que as crianças produzam uma cena a partir de uma provocação, que coloque em evidencia os carecimentos das crianças, de modo a deixá-las livres para exporem sua compreensão deste. Observando atentamente a construção das crianças, o professor pode, como indica Benjamin (2009, p. 114), propor "conteúdos, tarefas e eventos", sem ambicionar uma influência imediata sobre eles, ou seja, pode propor textos filosóficos e reflexões que contemplem os carecimentos e tensões observadas nessa relação entre os pares, de modo a proporcionar às crianças uma educação filosófica por meio da reflexão conjunta.

Esse espaço de leitura, discussão e reflexão filosófica possibilita às crianças, na interação com seus pares, uma outra relação com o conhecimento, reconhecendo que a criança aceita as coisas sérias também (Benjamin, 2009, p.55), desde que sejam honestas e espontâneas, respeitando e contemplando seus carecimentos.

Ao final desse processo pode-se propor uma apresentação que, como coloca o filósofo, caracteriza-se por ser uma síntese dos gestos até ali explorados pelas crianças que, organizada de modo inesperado e irrepetível, devido à efemeridade do teatro e ao fato da repetição na criança sempre se configurar como algo novo, acaba sendo uma "grande pausa criativa no trabalho educacional", visto que durante a apresentação, ao subirem ao palco, elas "ensinam e educam os atentos educadores", pois aqui vem à luz "novas forças, novas inervações" não previstas pelo professor (Benjamin, 2009, p. 118).

Apesar de sua sistematização dos jogos, vemos a tênue relação possível entre a proposta de Asja Lacis, teorizada por Walter Benjamin (Koudela, 1991, p. 26), e a metodologia de Viola Spolin (2010), pois em ambas se pressupõem que o "atuante se torna artesão de sua própria educação, produzida livremente por ele mesmo, embora dentro dos parâmetros de articulação de uma linguagem artística - o teatro e a improvisação teatral" (Koudela; Almeida Junior, 2015, p. 109).

Percebemos, como coloca Manoel de Barros (2010), que "o menino" vai aprendendo a usar as palavras, vendo que pode fazer "peraltagens" com elas, que também pode propulsionar sua relação com o outro e com o mundo através das suas enunciações, das suas produções cênicas e, processualmente, vai compreendendo as diferenças dos discursos, na arte e na vida. Entende que na arte pode "interromper o voo de um pássaro colocando um ponto no final da frase" (Barros, 2010) e que na vida esse "ponto" pode ter outras formas, outros meios, dar-se a partir de diversas ações. 


\section{Epílogo}

A partir desta investigação, parece-nos que aqui pode estar o sinal da possibilidade de uma barbárie no seu sentido positivo (Benjamin, 2009) na educação: a criança passa a ter outra relação com a linguagem, a filosofia, a arte, o social, a história e a memória, pois, através dos jogos teatrais e da improvisação, permite-se emergir os sinais secretos do vindouro, que falam através do gesto infantil.

Benjamin (2009, p. 119) via na prática de Asja Lacis a abertura para "uma força que aniquilará o posicionamento pseudorevolunionário do mais recente teatro da burguesia", nesse teatro infantil, produzido a partir da proposta de Lacis, não é a "propaganda de ideias que atua de maneira verdadeiramente revolucionária, propaganda que instiga aqui e ali ações irrealizáveis e perante a primeira consideração sóbria à saída do teatro se dá por vencida", mas sim sobre a ação, sobre a resolução coletiva das tensões, dos carecimentos.

Por isso é importante ressaltar que essa sugestão de uma prática aliando filosofia, jogos teatrais e improvisação não tem como intuito em-formar a criança, depositar nela conhecimentos à revelia, mas sim tornar o olhar do professor atento às crianças, tendo como papel mediar o processo educativo, observando os gestos infantis e conduzindo a prática de modo sutil, pois a proposta é de uma educação sob um contexto, proporcionando uma relação conhecimento-práxis e não uma imposição filosófica, de um modo de agir, pensar e viver.

Assim, defende-se aqui que a prática dos jogos teatrais e da improvisação pode possibilitar às crianças desenvolverem sua capacidade mimética e de comunicação, permitindo-se, na interação com seus pares, a explicitação de seus carecimentos, assim como a reflexão acerca das tensões que surgem, pois, como reforça Mafra (2010, p. 237), é em sua vida cotidiana que o indivíduo vai determinando seus carecimentos e dando aos outros conhecê-los, e o jogo teatral como contexto de formação, permite as crianças na interação com seus pares exporem-se (Benjamin, 2009, p. 115).

\section{Referências}

BARROS, Manoel. Poesia Completa. São Paulo: Leya Brasil, 2011.

BAKHTIN, Mikhail Mikhailovich. Arte e responsabilidade. In: BAKHTIN, M. M. (Mikhail Mikhailovich). Estética da Criação Verbal. São Paulo: WMF Martins Fontes, 2011.

BENJAMIN, Walter. Reflexões sobre a criança, o brinquedo e a educação. São Paulo: Editora 34, 2009.

BENJAMIN, Walter. Magia e técnica, arte e política: ensaios sobre literatura e história da cultura. 8. Ed. São Paulo: Brasiliense, 2012a. (Obras Escolhidas, v. 1).

BRASIL. Lei no 9.394, de 20 de dezembro de 1996. Estabelece as diretrizes e bases da educação nacional. Disponível em: http://www.planalto.gov.br/ccivil_03/leis/19394. htm. Acesso em: 30 jul. 2019. 
BUCK-MORSS, Susan. Dialética do Olhar: Walter Benjamin e o projeto das passagens. Tradução de Ana Luiza de Andrade; revisão técnica de David Lopes da Silva. Belo Horizonte: UFMG; Chapecó: Editora Universitária Argos, 2002.

GAGNEBIN, Jeanne Marie. Sete Aulas sobre linguagem, memória e história. Rio de Janeiro, Imago, 2005.

HELLER, Agnes. A filosofia radical. São Paulo: Brasiliense, 1983.

KOHAN, Walter Omar. A escola pública aposta no pensamento. Belo Horizonte: Autêntica, 2012.

KOUDELA, Ingrid Dormien. Brecht: um jogo de aprendizagem. São Paulo: Perspectiva, 1991.

KOUDELA, Ingrid Jogos Teatrais. São Paulo: Perspectiva, 2017.

KOUDELA, I. D.; SANTANA, A. P. Abordagens metodológicas do teatro na educação. Ciências Humanas em Revista, São Luís, v. 3, n.2, dezembro 2005.

KOUDELA, I. D.; ALMEIDA JUNIOR, José Simões de Almeida. Léxico de pedagogia do teatro. São Paulo: Perspectiva, 2015.

LAJOLO, Marisa. Infância de papel e tinta. In: FREITAS, Marcos Cezar. História Social da Infância no Brasil. São Paulo: Cortez, 2016.

LIPMAN, M. Filosofia vai à escola. São Paulo: Summus Editorial, 1990.

MAFRA, Leila. A Sociologia dos Estabelecimentos Escolares: Passado e Presente de um Campo de Pesquisa em ReConstrução. In: ZAGO; CARVALHO; VILELA (orgs.). Itinerários de Pesquisa. Perspectivas Qualitativas em Sociologia da Educação. Rio de Janeiro: DP\&A, 2003.

MATTHEWS, Gareth B. A Filosofia e a Criança. São Paulo: Martins Fontes, 2001.

MURANAKA, Fabiana. "Mas, o que se faz numa Sala de Filosofia?!!!" Uma análise do Eixo Educação pela Filosofia das Diretrizes Curriculares da Secretaria Municipal de Curitiba. Curitiba. 2007. 169f. Dissertação (Mestrado em Educação) - Setor de Educação, Universidade Federal do Paraná, Curitiba, 2007.

OLIVEIRA, Paula Ramos. Filosofia para a Formação da Criança. São Paulo: Pioneira Thompson Learning, 2004.

PEREIRA, Rita Marisa Ribes; JOBIM E SOUZA, Solange. Infância, conhecimento e con- 
temporaneidade. In: KRAMER, Sonia. Infância e produção cultural. Campinas: Papirus, 1998.

SPOLIN, Viola. Improvisação para o teatro. São Paulo: Perspectiva, 2010.

ZANINI, Raquel Aline. Educação filosófica e infância: o jogo teatral como possibilitador dessa relação a partir dos carecimentos das crianças. 2019. 125f. Dissertação (Mestrado em Educação) - Setor de Educação, Universidade Federal do Paraná, Curitiba, 2019.

Recebido em: 30/07/2019

Aprovado em: 05/11/2019 